\title{
MECHANICAL PROPERTIES OF HIGH STRENGTH ALUMUNUM ALLOYS
}

FORMED BY PULSED LASER DEPOSITION

\author{
J. A. KNAPP AND D. M. FOLLSTAEDT \\ Sandia National Laboratories, Albuquerque, NM 87185-1056
}

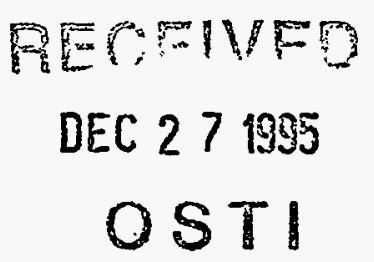

ABSTRACT :

Very high-strength alloys of $\mathrm{Al}(\mathrm{O})$ have been formed using a pulsed laser deposition (PLD) system to deposit from alternating targets of $\mathrm{Al}$ and $\mathrm{Al}_{2} \mathrm{O}_{3}$. Ion beam analysis and transmission electron microscopy show that the deposited material is uniform in composition . with up to 33 at.\% $\mathrm{O}$ and has a highly refined microstructure consisting of a fine, uniform dispersion of $\sim 1 \mathrm{~nm}$ diameter $\gamma-\mathrm{Al}_{2} \mathrm{O}_{3}$ precipitates. Ultra-low-load indentation testing combined with finiteelement modeling is used to determine the mechanical properties of the layers. Yield stresses as high as $5.1 \mathrm{GPa}$ have been measured in these materials, greatly exceeding the strengths of aerospace $\mathrm{Al}$ alloys $(0.5 \mathrm{GPa})$ and even high strength steels. The key to the properties of these materials is the dispersion of small, hard precipitates spaced only a few Burgers vectors apart; dislocations are apparently unable to cut through and must bow around them.

\section{INTRODUCTION}

Aluminum alloys are important for a number of applications and would be even more widely applied if not for relatively low strength and poor tribological properties. We have been investigating plasma-based synthesis methods for forming new alloys of aluminum with higher strength [1-3], motivated by the earlier discovery at our laboratory of precipitate-hardened $\mathrm{Al}(\mathrm{O})$ alloys using $\mathrm{O}$ implantation into bulk Al.[4-7] In the present paper we describe the formation of $\mathrm{Al}(\mathrm{O})$ alloys using a pulsed laser deposition (PLD) system; films of these alloys are formed by alternating depositions of $\mathrm{Al}$ and $\mathrm{Al}_{2} \mathrm{O}_{3}$, with each cycle kept under a monolayer.[1] Ion beam analysis shows that the resulting layers are of uniform composition in depth, with up to 33 at.\% $O$, while transmission electron microscopy (TEM) shows a highly refined microstructure consisting of a uniform dispersion of $\sim 1 \mathrm{~nm}$ diameter $\gamma-\mathrm{Al}_{2} \mathrm{O}_{3}$ precipitates in small grains (5-25 $\mathrm{nm}$ ) of fcc Al. This microstructure is similar to that formed earlier in the O-implanted Al materials, where testing showed yield stresses of 1-3 GPa [4-7] and improved tribological properties were observed.[7,8] Similar alloys have also been formed at our laboratory using deposition in an Electron Cyclotron Resonance system, another plasma-based method.[2,3]

We use nanoindentation testing combined with finite-element modeling of the indentation process to determine the mechanical properties of these layers. The finite-element modeling is essential because the deposited layer thickness is generally only a few times the maximum depth of indentation, so the load vs. depth response in the test is necessarily a combination of the properties of the substrate and of the layer. Using modeling, we have determined yield stresses as high as $5.1 \mathrm{GPa}$ in these PLD-formed materials, greatly exceeding the strengths of aerospace $\mathrm{Al}$ alloys $(\sim 0.5 \mathrm{GPa})$ and even high strength steels. Young's modulus is also determined by the modeling: values range from 120 to $160 \mathrm{GPa}$, versus $71.9 \mathrm{GPa}$ for pure $\mathrm{Al}$. The modeling procedure we have developed is expected to be widely applicable to other materials science studies of thin films; a description of the method will be the focus of this paper.

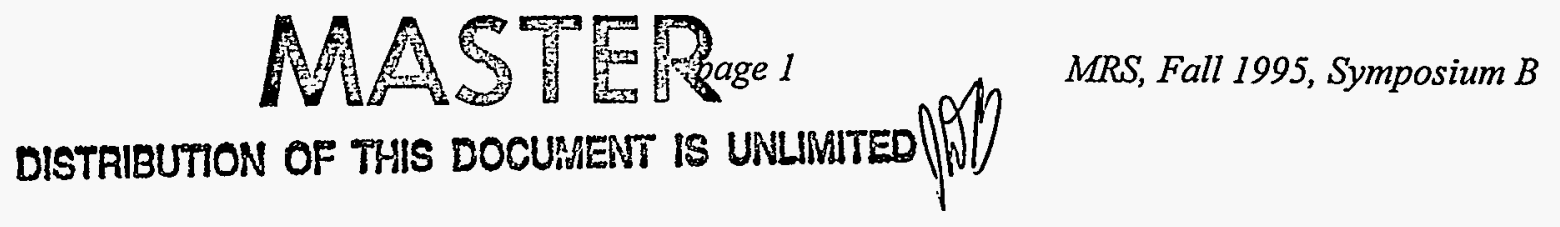




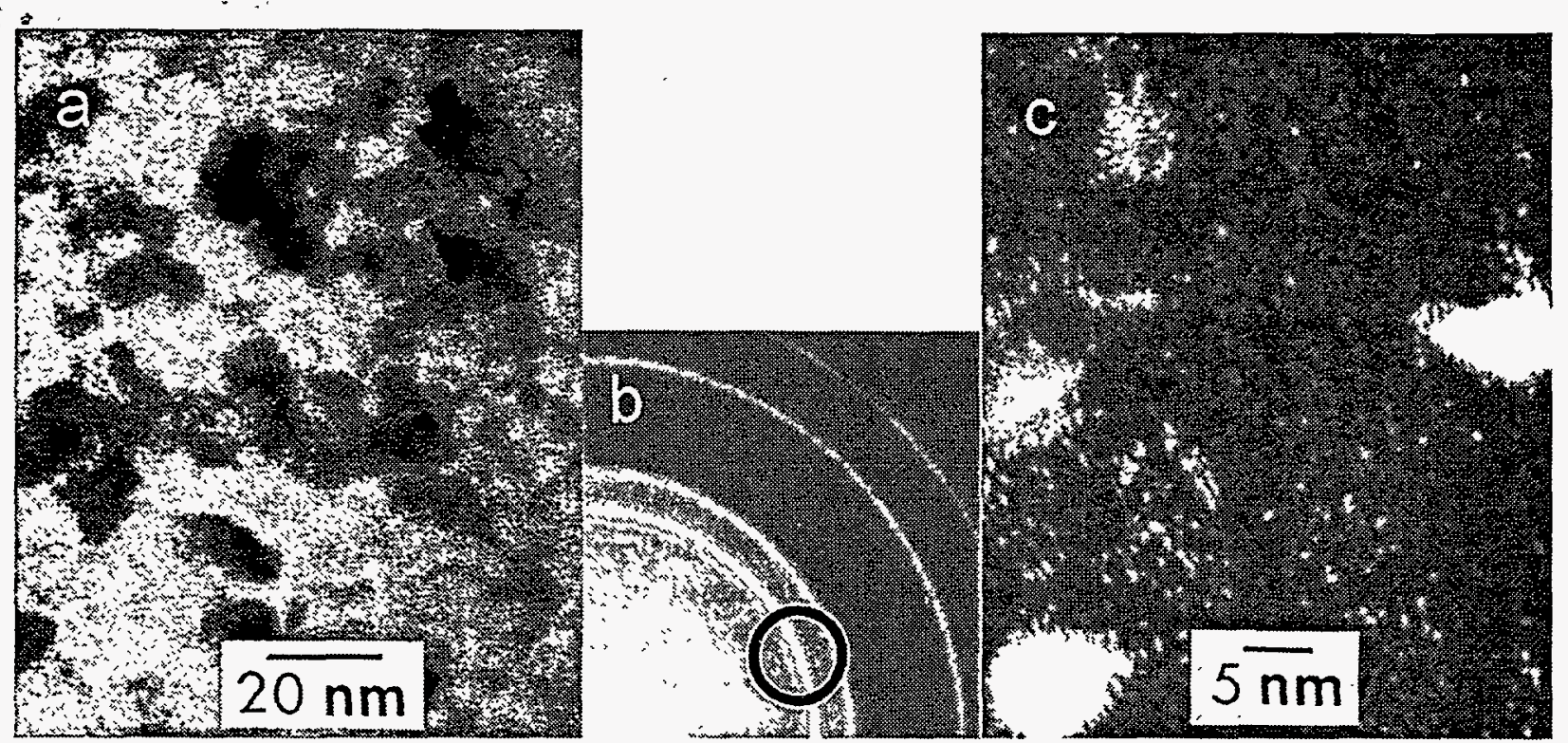

Figure 1. TEM images from a PLD layer with 31 at.\% O. (a) Bright-field image showing fcc Al grains 5-25 nm in diameter. (b) Electron diffraction pattern showing fcc Al rings. (c) Darkfield image using the diffraction aperture indicated in (b), showing 0.8-1.4 nm $\gamma-\mathrm{Al}_{2} \mathrm{O}_{3}$ precipitates in the $\mathrm{Al}$ matrix. Large white areas are $\mathrm{Al}$ grains in diffraction.

\section{ALLOY SYNTHESIS AND CHARACTERIZATION}

The layers were deposited in an all-metal vacuum chamber using a Q-switched Nd-YAG laser, frequency quadrupled to $266 \mathrm{~nm}$.[9] The pulse width was $20 \mathrm{~ns}$ at $10 \mathrm{~Hz}$, with a typical power density at the $\mathrm{Al}$ and $\mathrm{Al}_{2} \mathrm{O}_{3}$ targets of $1-2 \mathrm{~J} / \mathrm{cm}^{2}$. Deposition was done at room temperature on $<100>\mathrm{Si}$ or $\mathrm{Al}$ substrates and electron-transparent TEM grids. The composition of the layers was controlled by ablating from an $\mathrm{Al}$ target for $x$ shots, then switching to an $\mathrm{Al}_{2} \mathrm{O}_{3}$ target for $y$ shots, then back to $\mathrm{Al}$ and repeating. Each cycle was limited to less than a monolayer of material, resulting in uniform layers with the ratio of $x: y$ determining the composition. A recent addition to this deposition system is a particle filter interposed between target and substrate.[1] The filter is a slotted wheel spun at high speed, with the laser fired in synchronization with the slot position; the timing is such that the high-energy plasma component of the ablation plume passes through the slot to be quenched on the substrate, while the slower particles and droplets are blocked by the wheel. This filter dramatically improved the smoothness of the $\mathrm{Al}(\mathrm{O})$ films and greatly reduced subsequent scatter in the nanoindentation results. Without the filter, particles and droplets are a particular problem with these layers because of the tendency of the Al target to overheat and splatter droplets onto the sample.

After deposition the film thickness and composition were characterized by Rutherford backscattering spectrometry. The measured $\mathrm{O}$ concentrations were up to 33 at. $\%$ and uniform across the layers to within \pm 2 at.\%. For Transmission Electron Microscopy (TEM), some depositions were performed simultaneously on electron-transparent grids as well as the $\mathrm{Si}$ or $\mathrm{Al}$ substrates. Examination of the layers revealed very fine-grained fcc Al. Imaging in darkfield showed a very dense distribution of $\gamma-\mathrm{Al}_{2} \mathrm{O}_{3}$ precipitates like that observed in ion-implanted $\mathrm{Al}$, and which is thought to be responsible for the high strength of the earlier layers.[4-8] Figure 1 illustrates the results for a 31 at.\% O layer produced by PLD. In panel (a) is a bright-field micrograph showing the Al structure with grains $5-25 \mathrm{~nm}$ in diameter. Panel (b) shows a diffraction pattern from the layer. Because diffraction from the $\gamma-\mathrm{Al}_{2} \mathrm{O}_{3}$ precipitates underlies the rings from fcc $\mathrm{Al}$ [2], imaging in darkfield with the aperture shown in the figure will illuminate 
not only some of the $\mathrm{Al}$ grains brightly, as expected, but also a high density of the very small precipitates which lie within other, weakly diffracting $\mathrm{Al}$ grains. Figure 1(c) shows such a micrograph, with a few $\mathrm{Al}$ grains in the Bragg condition (the large white areas) and numerous small $\gamma-\mathrm{Al}_{2} \mathrm{O}_{3}$ precipitates, ranging in size from 0.8 to $1.4 \mathrm{~nm}$. Previous TEM examination of $\mathrm{O}-$ implanted $\mathrm{Al}$ has shown that these precipitates are coherent with each fcc $\mathrm{Al}$ grain they occupy.[2]

\section{NANOINDENTATION TESTING AND FINITE-ELEMENT MODELING}

Nanoindentation was used to measure the mechanical properties of these layers after deposition.[10] Figure 2 shows typical results from testing three samples: two different PLDformed $\mathrm{Al}(\mathrm{O})$ alloys and a pure $\mathrm{Al}$ evaporated layer, all deposited on $\mathrm{Si}$. In the test, a pyramidal diamond tip is pushed into the material under very fine load control and the reaction force is recorded as a function of depth. For these samples, the pin was inserted to $100 \mathrm{~nm}$, held at constant load for 15 seconds, withdrawn, inserted at the same spot to $200 \mathrm{~nm}$, held for 15 seconds, then withdrawn a second time. During the hold segments the sample is thought to relax through creep, allowing the indenter to push in to greater depths; this is reflected by the horizontal sections in each curve. The apparent hardness of each sample is shown by the slope and height of the loading portion of the curves, while the elastic properties are reflected in the slope of the curve during the unloading segments. For each sample a series of 10 indents were performed, spaced $15 \mu \mathrm{m}$ apart. For bulk samples, the hardness and Young's modulus $\mathrm{E}$ of the material can be

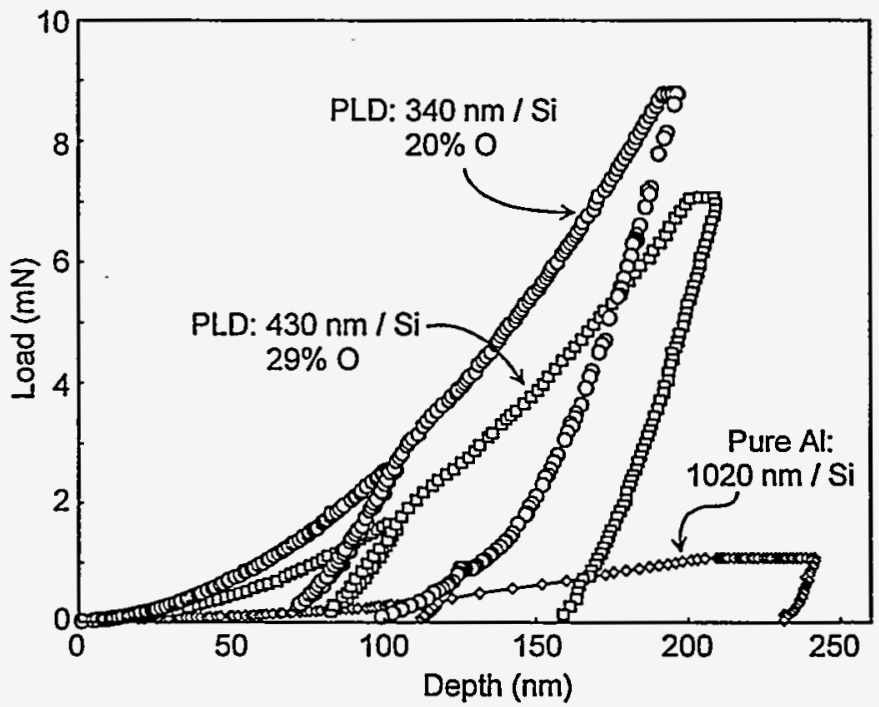

Figure 2. Load vs. depth response curves for two PLD $\mathrm{Al}(\mathrm{O})$ alloys and an evaporated, pure $\mathrm{Al}$ layer, all deposited on $\mathrm{Si}(100)$. extracted directly from the data.[11] However, for thin film samples, especially with a layer whose thickness is only a few times the maximum depth of the indent, the load response is a combination of the mechanical response of the layer and that of the substrate. However, even without detailed analysis, Fig. 2 clearly shows that the PLD layers are much harder than the pure Al layer, with much less creep and a somewhat stiffer elastic response.

In order to separate the properties of the layers from those of the substrate, finite-element modeling of the indent process was used, varying the input parameters for the surface alloy until a suitable match to experiment was found. We are using the iterative static solver in the Explicit version of ABAQUS [12], a pre-conditioned conjugate gradient solver tuned for large, nonlinear problems. This code allows modeling the surface interactions in the problem and is more efficient both in time and memory usage than a direct solver. Typical run times for a 2dimensional mesh with 2000 elements are 30-40 minutes on a DEC AlphaStation 250 4/266; a 3-dimensional mesh with $\sim 7000$ elements runs in 5-10 hours. A further advantage of using this commercial code is its wide availability, easing the transfer of our methods to other laboratories.

Figure 3 shows examples of both a 2-dimensional, axisymmetric mesh and a 3-dimensional mesh. Both meshes are set up to model the $340 \mathrm{~nm}$ thick PLD sample, and are shown after the simulation has run to $200 \mathrm{~nm}$ depth. Meshes are generated specific to each sample structure, and 

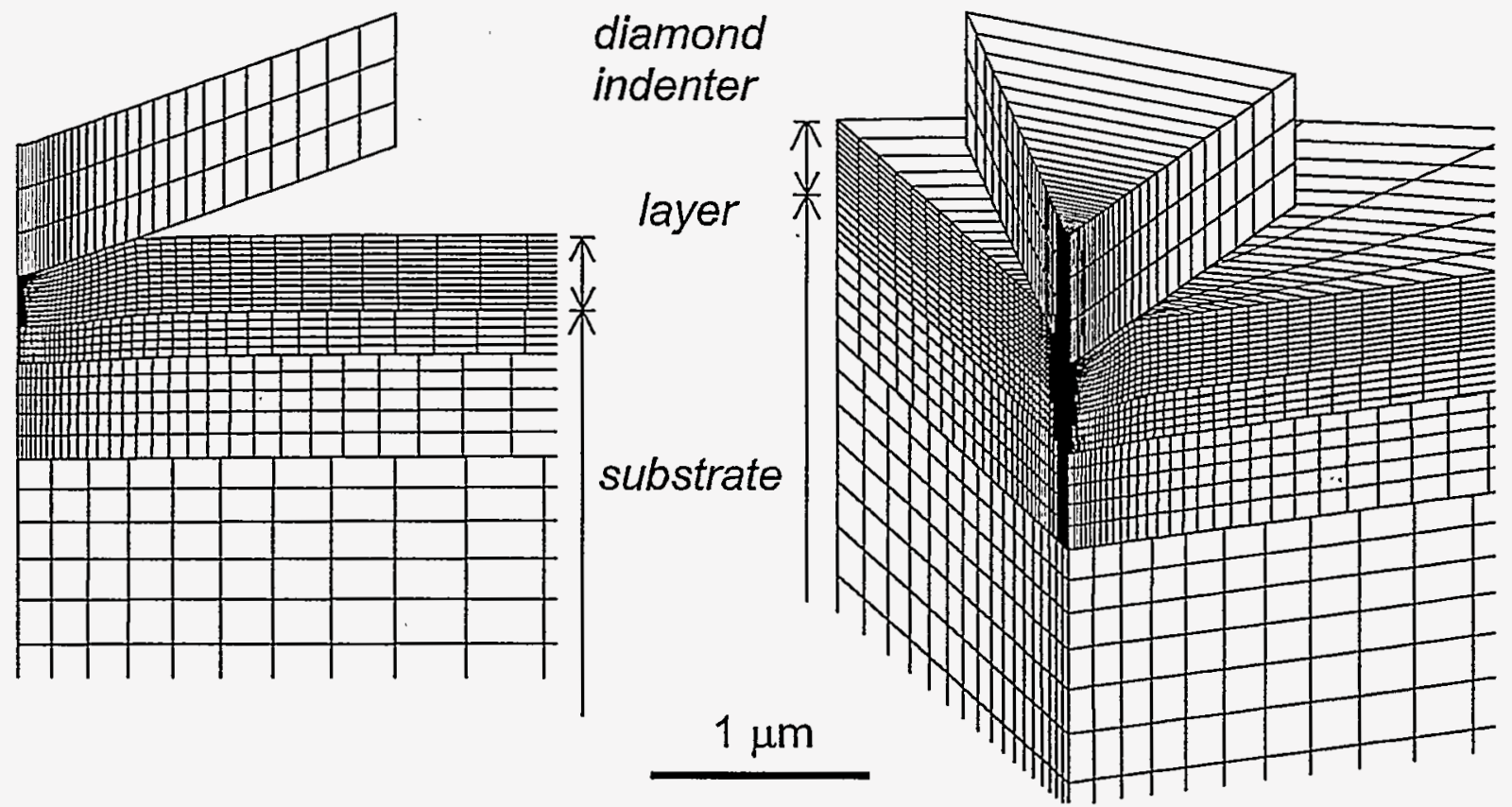

Figure 3. Typical meshes used in ABAQUS simulations, with the indenter shown at $200 \mathrm{~nm}$ depth in both cases. The 3-dimensional mesh models a $60^{\circ}$ section of the sample and pin because of the pyramidal symmetry of the indenter pin.

include the pin shape (area vs. depth) as supplied by Nano Instruments with the experimental data. The 2D mesh uses cylindrical symmetry and models the pin as a cone, while the 3D mesh models it with the actual pyramidal shape, modified by the area function. Because of symmetry it is only necessary to model a $60^{\circ}$ section of the pin and sample. The size of the meshes is generally $6 \mu \mathrm{m}$ deep by $6 \mu \mathrm{m}$ radius; only the portions near the center are shown in the figure.

For each material, the density, Young's modulus E, Poisson's ratio, and a stress-strain curve were input. The diamond was modeled as an elastic solid using published parameters. The Si was modeled as an elastic-plastic material with no work hardening; E from the literature was used, but the yield stress $\sigma_{Y}$ for $\mathrm{Si}$ was determined by separate indentation testing and modeling of a bare Si sample. The Al(O) layers were modeled as elastic-plastic solids, using the classical metal plasticity model in ABAQUS with a Mises yield surface and associated plastic flow. Poisson's ratio for pure $\mathrm{Al}$ was used, and the hardening rate was fixed for all simulations at 1.5 $\mathrm{GPa}$, a value which appears from the literature to be typical of most $\mathrm{Al}$ alloys and $\mathrm{Al}$ with impurities.[13] The initial stress in the layer (tensile or compressive) can also be input, but for most simulations this was left at zero, as was the friction between tip and layer surface. The two main parameters which were varied to fit the simulation to the experimental results were $\sigma_{Y}$ (defined at a plastic strain of .002), and $\mathrm{E}$. The loading portion of the indentation response curve is sensitive to both $\sigma_{Y}$ and $\mathrm{E}$, while the unloading portion is determined largely by $\mathrm{E}$.

Figure 4 shows a diagram of the procedure we developed for finding a good fit to the experimental response for each sample with a minimum of computer runs. First a series of 5-6 simulations are run with values of $\sigma_{Y}$ and $E$ selected to approximately bracket the expected experimental values. Then the loading and unloading slopes of all experimental response curves and all simulations are extracted and put in a spreadsheet. These are represented by a 2D plot in Fig. 4. The experimental points are the squares clustered in the center, while the simulations are the triangular points. Since each point (loading vs. unloading slope) depends on both $\sigma_{Y}$ and $E$, 


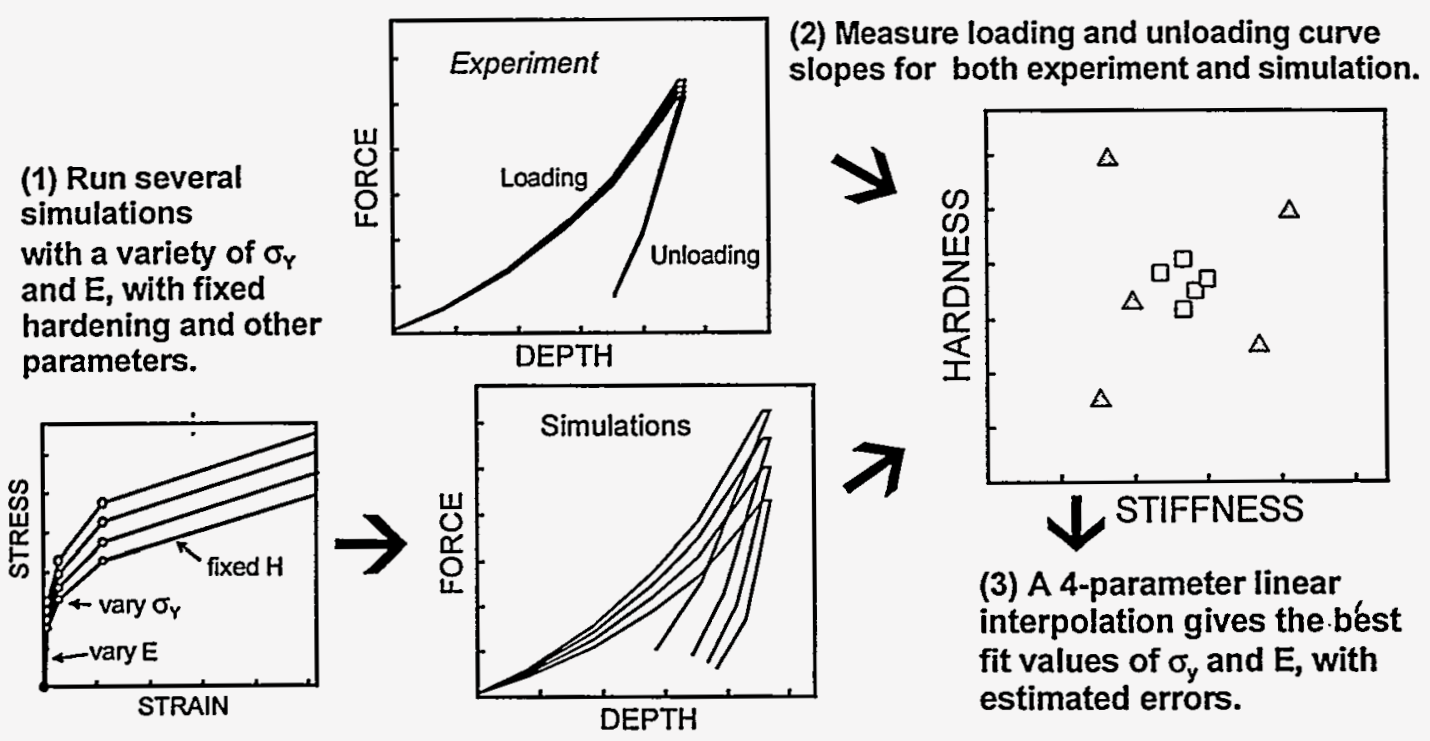

Figure 4. Schematic of the procedure for finding a best fit of the simulation to the experimental indentation load curves with a minimum of runs.

the plot is a $2 \mathrm{D}$ projection of a 4-parameter space. The extrapolation to a best fit is accomplished by averaging the experimental points, followed by a 4-parameter linear interpolation of the simulation points to that average value. This procedure gives the projected values of $\sigma_{Y}$ and $E$ which should, when used in a simulation, give a response curve that matches the "average" experimental curve. It also gives error bounds on $\sigma_{Y}$ and $E$ based on both the spread in the experimental results and the quality of the linear interpolation. The procedure assumes that the dependence of the two slopes on $\sigma_{Y}$ and $E$ is linear for both, but we have found this to be a good approximation when the initial bracketing values for $\sigma_{Y}$ and $E$ are reasonably close to the final values. One or two additional simulations are performed to confirm that the interpolated values give a good fit to experiment. The value of this procedure lies both in providing a good fit in a minimum of iterations and in quantifying the error bars for the final values of $\sigma_{Y}$ and $E$.

Figure 5 shows the best fit simulations for the two PLD layers of Fig. 2. The solid and dashed lines are 2D axisymmetric simulations for the 20 and 29 at.\% layers, respectively. An additional simulation using a $3 \mathrm{D}$ mesh with the same $\sigma_{Y}$ and $\mathrm{E}$ is given for the $20 \%$ layer, showing that the $3 \mathrm{D}$ and $2 \mathrm{D}$ approaches give essentially identical results until the simulation reaches $\sim 150 \mathrm{~nm}$. The discrepancy at deeper depths may be due to an incorrect modeling of the shape of blunting for the 3D tip and is under further investigation. The following values were deduced using 2D modeling: (1) 20 at.\% $\mathrm{O}$; $\sigma_{\mathrm{Y}}=5.1 \pm 0.2 \mathrm{GPa}$ and $\mathrm{E}=160 \pm 10 \mathrm{GPa}$, and (2) 29 at.\% $\mathrm{O} ; \sigma_{\mathrm{Y}}=2.4 \pm 0.2 \mathrm{GPa}$ and $\mathrm{E}=114 \pm 10 \mathrm{GPa}$. The remarkable value of $5.1 \mathrm{GPa}$ for the $20 \%$ sample should be compared to $0.041 \mathrm{GPa}$ for the yield stress of soft, pure $\mathrm{Al}$ and $0.5 \mathrm{GPa}$ for 7075-T6 aerospace $\mathrm{Al}$ alloy.

There are several uncertainties which might effect the results. The effect of creep cannot be modeled at present; the materials parameters we use are all time-independent. Residual stress in deposited layers is known to affect their indentation response [14]; we did simulations with both initial compressive and tensile stresses in the layer and found that a tensile stress of $100 \mathrm{MPa}$ would increase the derived $\sigma_{Y}$ for the $20 \%$ sample to $5.2 \mathrm{GPa}$. Since we have not measured the stress level, all the above results were derived with no initial stress. The strength of bonding between layer and substrate is also unknown; we assumed an unyielding interface. Finally, the precise shape of the tip, particularly at these shallow indents, may not be sufficiently well known. However, even with all these modeling uncertainties considered, we judge the absolute uncertainty in our results to be no more than $20 \%$. 


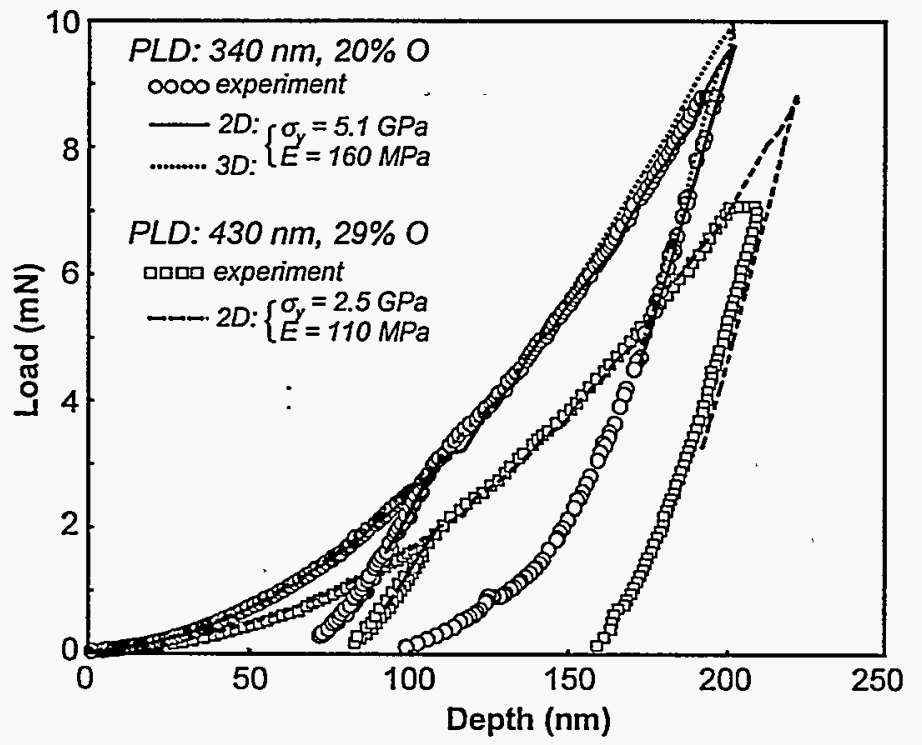

Figure 5. Finite-element simulations of nanoindentation results from two PLD alloy layers on Si. Both $2 \mathrm{D}$ and $3 \mathrm{D}$ simulations are shown for the 20 at.\% O layer.

\section{ACKNOWLEDGMENTS}

Discussions and collaborations with J. C. Barbour and S. M. Myers were very valuable. Technical assistance by J. R. Bigbie, M. P. Moran and J. C. Banks is gratefully acknowledged. This work was performed at Sandia National Laboratories under the auspices of the U.S. Department of Energy and funded by its Office of Basic Energy Sciences, Div. of Materials Sciences, under contract no. DE-AC04-94AL85000. This work is also part of the BES Synthesis and Processing Center's project on Processing for Surface Hardness.

\section{REFERENCES}

1. J. A. Knapp, D. M. Follstaedt, and S. M. Myers, J. Appl. Phys., in press.

2. D. M. Follstaedt, J. A. Knapp, J. C. Barbour, S. M. Myers and M. T. Dugger, Proc. of the Int. Conf. on Beam Processing of Advanced Materials, 10/30-11/2/95, in press.

3. J. C. Barbour, D. M. Follstaedt, and S. M. Myers, Nucl. Instr. \& Meth. $\underline{B}$, in press.

4. R. J. Bourcier, S. M. Myers and D. H. Polonis, Nucl:'Instr. \& Meth. B44 (1990). 278.

5. R. J. Bourcier, D. M. Follstaedt, M. T. Dugger and S. M. Myers, Nucl. Instr. \& Meth. B59/60 (1991) 905.

6. D. M. Follstaedt, S. M. Myers and R. J. Bourcier, Nucl. Instr. \& Meth. B59/60 (1991) 909.

7. D. M. Follstaedt, S. M. Myers, R. J. Bourcier and M. T. Dugger, Proc. of the Int. Conf. on Beam Processing of Advanced Materials, 11/2-5/92, (TMS, Warrendale, PA, 1993) 507.

8. M. T. Dugger, R. J. Bourcier, D. M. Follstaedt, and S. M. Myers, Tribology International, in press.

9. J. A. Knapp, Mat. Res. Soc. Symp. Proc. 236 (1992) 473.

10. Nanoindentation tests were performed at Nano Instruments, Inc., Knoxville, TN.

11. W. C. Oliver and G. M. Pharr, J. Mater. Res. 7 (1992) 1564.

12. ABAQUS/Explicit version 5.4, Hibbitt, Karlsson \& Sorensen, Inc., Pawtucket, RI.

13. Atlas of Stress-Strain Curves, Edited by H. E. Boyer (ASM International, Metals Park, Ohio, 1987) 383.

14. G. M. Pharr, T. Y. Tsui, A. Bolshakov and W. C. Oliver, Mat. Res. Soc. Symp. Proc. $\underline{338}$ (1994) 127. 


\section{DISCLAIMER}

This report was prepared as an account of work sponsored by an agency of the United States Government. Neither the United States Government nor any agency thereof, nor any of their employees, makes any warranty, express or implied, or assumes any legal liability or responsibility for the accuracy, completeness, or usefulness of any information, apparatus, product, or process disclosed, or represents that its use would not infringe privately owned rights. Reference herein to any specific commercial product, process, or service by trade name, trademark, manufacturer, or otherwise does not necessarily constitute or imply its endorsement, recommendation, or favoring by the United States Government or any agency thereof. The views and opinions of authors expressed herein do not necessarily state or reflect those of the United States Government or any agency thereof. 


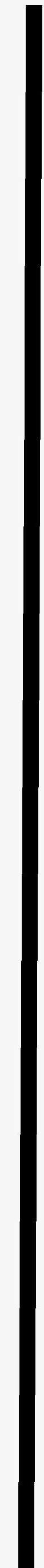

